\title{
Erratum to: Facilitating the Design/Evaluation Process of Web-Based Geographic Applications: A Case Study with WINDMash
}

\author{
The Nhan Luong ${ }^{1(\bowtie)}$, Christophe Marquesuzaà ${ }^{2}$, Patrick Etcheverry ${ }^{2}$, \\ Thierry Nodenot ${ }^{2}$, and Sébastien Laborie ${ }^{2}$ \\ 1 Faculty of Computer Science and Engineering, \\ Ho Chi Minh City University of Technology, \\ 268 Ly Thuong Kiet Street, District 10, Ho Chi Minh City, Vietnam \\ nhan@hcmut.edu.vn \\ ${ }^{2}$ Université de Pau et des Pays de l'Adour, Laboratoire d'informatique, \\ EA 3000, 64600 Anglet, France \\ \{christophe.marquesuzaa, patrick. etcheverry, \\ thierry.nodenot, sebastien.laborie\}@iutbayonne. \\ univ-pau. fr
}

\section{Erratum to: \\ Chapter "Facilitating the Design/Evaluation Process of Web-Based Geographic Applications: A Case Study with WINDMash" in: T.K. Dang et al. (Eds.): Future Data and Security Engineering, LNCS 9446, https://doi.org/10.1007/978-3-319-26135-5_19}

In the originally published version of this paper the affiliation of the first author, The Nham Luong, contained a punctuation mistake due to which the city was incorrectly stated as "Chi Minh City" instead of "Ho Chi Minh City". The affiliation of the authors Christophe Marquesuzàa, Patrick Etcheverry, Thierry Nodenot, and Sébastien Laborie was incorrectly stated as “T2i - LIUPPA, Université de Pau et des Pays de l'Adour, 2 Allée du Parc Montaury, 64600 Anglet, France”. This has been corrected.

The updated online version of this chapter can be found at https://doi.org/10.1007/978-3-319-26135-5_19 